\title{
Tool Efficiency Analysis model research in SEMI industry
}

\author{
MA Lei*, ZHANG Nana, ZHANG Zhongqiu \\ Northwestern Polytechnical University Ming De College, Xi'an, China
}

\begin{abstract}
One of the key goals in SEMI industry is to improve equipment through put and ensure equipment production efficiency maximization. This paper is based on SEMI standards in semiconductor equipment control, defines the transaction rules between different tool states, and presents a TEA system model which is to analysis tool performance automatically based on finite state machine. The system was applied to fab tools and verified its effectiveness successfully, and obtained the parameter values used to measure the equipment performance, also including the advices of improvement.
\end{abstract}

\section{Introduction}

In semiconductor manufacturing industry, production tools are the most important part of the whole fab, usually they are very expensive and have higher human maintenance costs. So the biggest concern of semiconductor factory is how to improve fab tools performance, how to improve the productivity and yield, and how to reduce scrap.

Most of fab in global wide use automation application which are mainly focus on SPC and Run to Run control in recent years. Both of SPC and R2R are working during production process, they can monitor and forecast product quality by statistical analysis of recipe parameter. But from the perspective of equipment, how to analysis tools' performance and find out the reason why production efficiency is not high, how to realize tools' fullest utilization are still in an primary stage, so they could be a key point of semiconductor manufacturing industry's development direction in the future.
This paper is on the basis of SEMI international standard, presents an automation model to analysis production equipment's performance by finite state machine and verify its efficiency, finally analysis the operation result of this model and come to a conclusion.

\section{Basic knowledge}

\subsection{Basic states of tool}

Before analysis tool's performance and utilization, there should define tool states in each stage. In SEMI E10 standard, they defined 6 basic states for tools.

(1) Non-Scheduled State; (2) Unscheduled Down State; (3) Scheduled Down State;

(4) Engineering State; (5) Standby State; (6) Productive State.

Figure 1 and Figure 2 describe the six basic equipment states defined in SEMI E10.

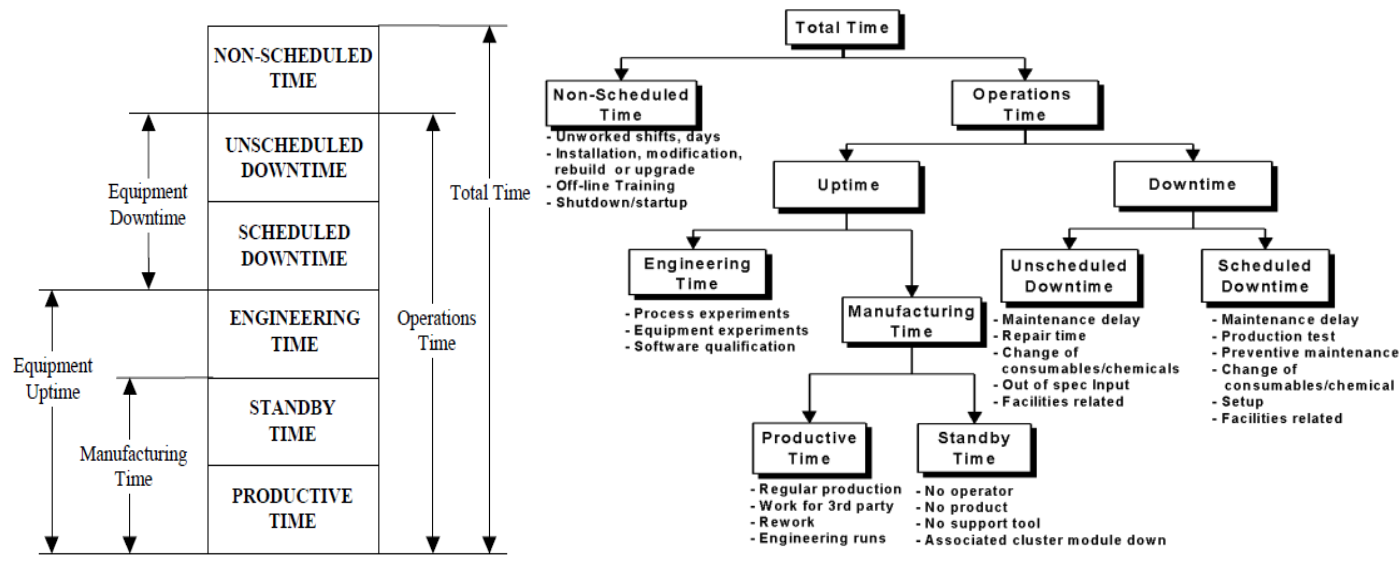

Figure 1. SEMI E10 Equipment States Stack Chart Figure2. SEMI E10 Summary of Time

*Corresponding Author. E-mail: 357023814@qq.com 


\subsection{Equipment productivity measurement}

An OEE (Overall Equipment Effectiveness) concept is given in E79, the calculation method is listed below:
Overall Equipment Efficiency (OEE) = (Availability Efficiency) X (Performance Efficiency) X (Quality Efficiency).

Availability Efficiency $=($ Equipment Uptime $) \div$ (Total Time);

Performance Efficiency $=($ Operational Efficiency $) X$ (Rate Efficiency);

Operational Efficiency $=$ (Production Time $) \div$ (Equipment Uptime);

Rate Efficiency $=($ Theoretical Production Time for Actual Units) $\div$ (Production Time);

Theoretical Production Time for Actual Units =I (Actual Units of Recipe I x THTI);

Theoretical Production Time for Effective Units $=\mathrm{I}$ (Effective Units of Recipe I x THTI);

THTI $=$ theoretical production time per unit of recipeI;
Quality Efficiency $=($ Theoretical Production Time for Effective Units) - (Theoretical Production Time for Actual Units);

In order to calculate tool OEE value accurately to judge its performance, TEA (Tool Efficiency Analysis) model is presented in the following paper. The advantages of this model are to calculate each parameter of tool performance and find out the reason which affect tool performance through data analysis.

\section{Model introduction 3.1 TEA model framework}

TEA model includes ADC (Automation Data Collection) and DA (Data Analysis) two parts.

(1) Automation Data Collection Framework

ADC is divided into three modules: event trigger, event mapping module, and states change engine, as shown in figure 3 .

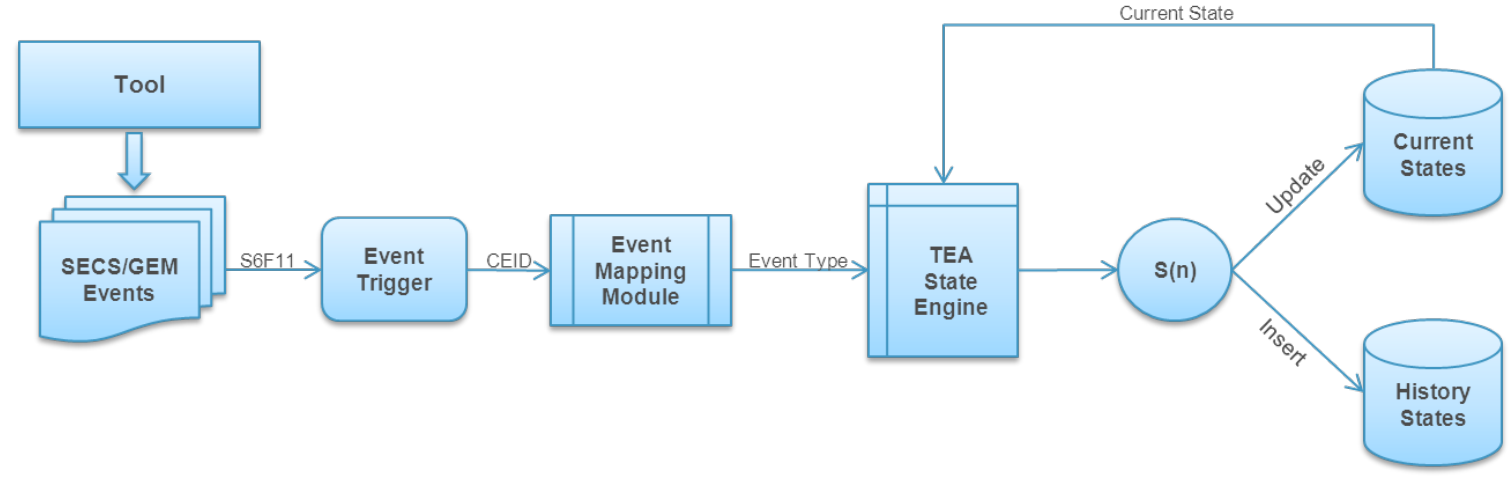

Figure 3. TEA data collection framework

Event Trigger is responsible for capturing S6F11 message reported by tool and retrieving collection event ID (CEID) value. SEMI communication standard uses SECS/GEM, which defined the communication rules between tools and host, tools and tools. S6F11 is one of message format defined in SECS/GEM, it has been used for sending event from tool to host.

Event Mapping Module is responsible for relationship mapping between event CEID captured by event trigger and pre-defined event in TEA system and return this captured event's type. The relationship mapping table is based on event definition in tool manual, mapping example is like below:

Table 1. TEA event mapping example

\begin{tabular}{|l|l|}
\hline CEID & Event Type \\
\hline 500 & Material Placed \\
\hline 1000 & Wafer Start \\
\hline 1001 & Wafer End \\
\hline
\end{tabular}

\begin{tabular}{|l|l|}
\hline 600 & Material Removed \\
\hline$\ldots \ldots \ldots \ldots$ & $\ldots \ldots \ldots \ldots$ \\
\hline
\end{tabular}

TEA State Engine defined tools' all states, including each parent state and sub state. It records tool current state according to the event type, and changes tool current state when certain conditions are met and saved the result into database. The detail is below:

Define a finite state machine $A=\left(Q, \sum, \delta, s, F\right)$ :

- $\quad Q$ is non-empty finite state set, including all sub state, as shown in table 2;

- $\quad \sum$ is non-empty finite character set, which defined all the event type;

- $\delta$ is transition function, $\delta\left(S_{c}, \sigma\right)=S_{d}\left(S_{c}, S_{d} \epsilon\right.$ $\left.Q, \sigma \epsilon \sum\right)$;

- $\quad s$ is initial state, $s \in Q$;

- $F$ is accepted state set, $F \leq Q$.

$S_{d}$ is destination state, $S_{c}$ is current state, their mapping relationship when certain event type $\sigma\left(\sigma \epsilon \sum\right)$ received is defined in $\delta$ transition function. As shown in table 3. 
Table 2. State of the machine definition

\begin{tabular}{|c|c|}
\hline Parent State & Sub State \\
\hline \multirow{4}{*}{ Productive } & Productive/Processing \\
\cline { 2 - 2 } & Productive/Processing/Step1 \\
\cline { 2 - 2 } & Productive/Processing/Step2 \\
\cline { 2 - 2 } & $\ldots \ldots \ldots \ldots \ldots$ \\
\hline \multirow{2}{*}{ Standby } & Standby/Door_Opened \\
\cline { 2 - 2 } & Standby/Material_Loaded \\
\cline { 2 - 2 } & Standby/ReadyForUnload \\
\cline { 2 - 2 } & $\ldots \ldots \ldots \ldots \ldots \ldots$ \\
\hline Engineering & Engineering \\
\hline Scheduled_Down & Scheduled Down Time \\
\hline Unscheduled_Down & Unscheduled Down Time \\
\hline Non_Scheduled & Non-Scheduled Time \\
\hline
\end{tabular}

Table 3. State transition rules

\begin{tabular}{|l|l|l|}
\hline Current State & Destination State & Event Type \\
\hline Standby & Productive/Processing & Wafer Start \\
\hline Productive/Processing & Productive/Processing/Step1 & Step Change \\
\hline Productive/Processing & Standby & Wafer End \\
\hline$\ldots \ldots$ & $\cdots \cdots$ & $\cdots \cdots$ \\
\hline
\end{tabular}

Its main function is to analysis data retrieved by data

\section{Data Analysis Framework}

Data Analysis is divided into two modules: DSM (Data Statistics Module) and DCM (Data Calculation Module).

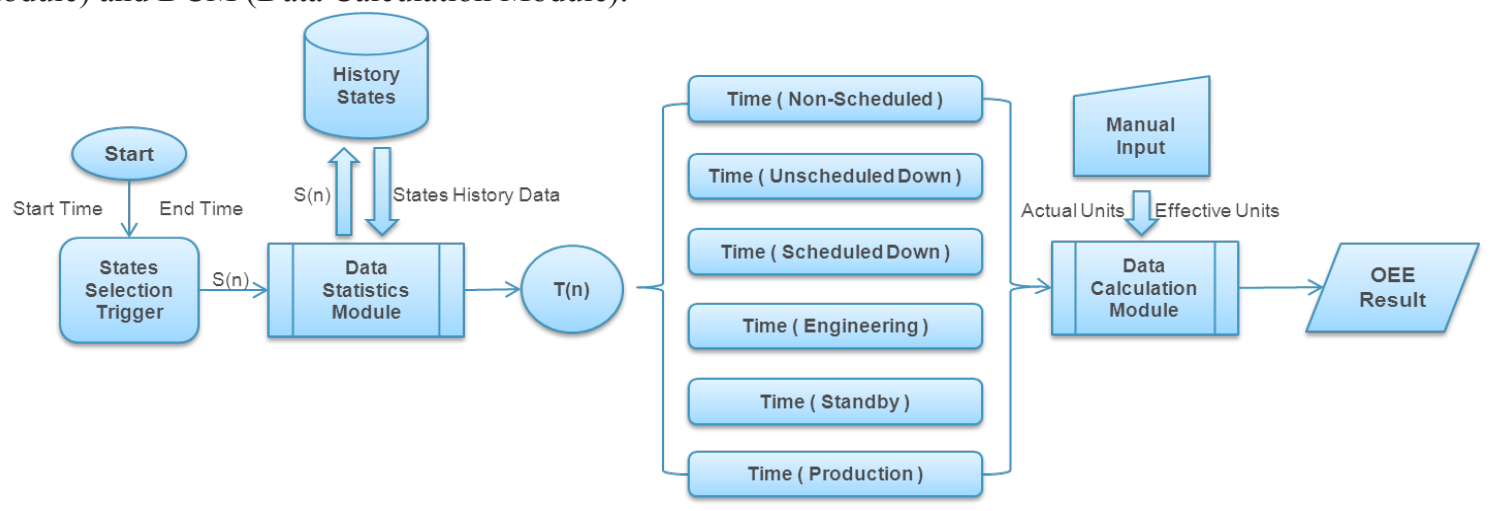

Figure4. Data Analysis Framework

Data Analysis model filters valid data based on time range selected by user, and calculates six states' time separately in this time range. The data source is in History States table in Data Statistics Module. Data Calculation 
Module calculates OEE value based on production time per unit and total time which according to the six states time, actual units and effective units.

\section{Experiment, Example calculations}

The calculations in this section are based on a seven-day period sample dataretrieved by Data Collection module, and calculate the following states data by Data Analysis module:

\begin{tabular}{|c|c|c|l|l|}
\hline Recipe & $\begin{array}{l}\text { Theoretical Production } \\
\text { Time (hr/wafer) }\end{array}$ & $\begin{array}{l}\text { Theoretical } \\
\text { Production } \\
\text { Number(wafer/ hr) }\end{array}$ & $\begin{array}{l}\text { Actual } \\
\text { ProductionNumber }\end{array}$ & $\begin{array}{l}\text { Production } \\
\text { Number }\end{array}$ \\
\hline A & 0.03333 & 30 & 1420 & 1400 \\
\hline B & 0.04000 & 25 & 600 & 600 \\
\hline C & 0.05000 & 20 & 800 & 800 \\
\hline D & 0.06667 & 15 & 500 & 480 \\
\hline
\end{tabular}

Data Calculation Module calculates like below:

- Equipment Uptime

$=($ Production Time $)+($ Standby Time $)+$

(Engineering Time)

$=(147.00$ hours $)+(6.00$ hours $)+(3.00$ hours $)$

$=156.00$ hours

- $\quad$ Production Time (given)

Theoretical Production Time for Actual Units

= $\mathrm{i}$ (Actual Units of Recipe $i$ X THTi)

$=[(1420$ units $X 0.03333 \mathrm{hr} /$ unit $)$

$+(600$ units X $0.04000 \mathrm{hr} /$ unit $)$

$+(800$ units X $0.05000 \mathrm{hr} /$ unit $)$

+ (500 units X0 $066667 \mathrm{hr} /$ unit $)]$

$=144.66$ hours

- $\quad$ Theoretical Production Time for Effective Units

$=\mathrm{i}$ (Effective Units of Recipe $i$ XTHTi)

$=[(1400$ units $X 0.03333$ hr/unit $)$

$+(600$ units X 0.04000 hr/unit $)$

$+(800$ units X 0.05000 hr/unit)

$+(480$ units X $0.06667 \mathrm{hr} /$ unit)]

$=142.67$ hours

- Availability Efficiency
- $\quad$ Non-Scheduled Time

0.00 hours

- Unscheduled Downtime

4.00 hours

- Scheduled Downtime

8.00 hours

- Engineering Time

3.00 hours

- Standby Time 6.00 hours

- $\quad$ Production Time 147.00 hours

- Total Time 168.00 hours
$=($ Equipment Uptime $) \div($ Total Time $)$

$=(156.00$ hours $) \div(168.00$ hours $)$

$=0.9286$

- Operational Efficiency

$=($ Production Time $) \div($ Equipment Uptime $)$

$=(147.00$ hours $) \div(156.00$ hours $)$

$=0.9423$

- Rate Efficiency

= (Theoretical Production Time for Actual Units)

$\div \quad$ (Production Time)

$=(144.66$ hours $) \div(147.00$ hours $)$

$=0.9840$

- Performance Efficiency

= (Operational Efficiency) $x$ (Rate Efficiency)

$=(0.9423) X(0.9840)$

$=0.9272$

- Quality Efficiency

= (Theoretical Production Time for Effective

Units)

$\div \quad$ (Theoretical Production Time for Actual Units)

$=(142.67$ hours $) \div(144.66$ hours $)$

$=0.9862$ 
- Overall Equipment Efficiency (OEE)

$=($ Theoretical Production Time for Effective

Units)

$\div$ (Total Time)

$=(142.67$ hours $) \div(168.00$ hours $)$

$=0.8492$
OEE is the key indicator of measuring tool

performance. According to the OEE value fab customer

can find out how to improve tool efficiency and

performance, as shown in Figure 5. This experiment

calculates the OEE value of the test tool and verify the

validation of the TEA model finally.

\begin{tabular}{|c|c|c|c|}
\hline E1O States & \multicolumn{3}{|c|}{$\begin{array}{l}\text { E79 Productivity Losses and } \\
\text { Improvement Domains }\end{array}$} \\
\hline Non-Scheduled Time & \multirow{8}{*}{$\begin{array}{c}\text { Theoretical } \\
\text { Production } \\
\text { Time for } \\
\text { Actual Units }\end{array}$} & \multirow{3}{*}{$\begin{array}{c}\text { Availability Efficiency } \\
\text { Losses } \\
\text { (Supplier and User Domain) }\end{array}$} & \multirow{6}{*}{$\begin{array}{l} \\
--- \\
\text { Pefformance } \\
\text { Efficiency } \\
\text { Losses } \\
\text { (Supplier and } \\
\text { User Domnin) } \\
\mathbf{\square}\end{array}$} \\
\hline Scheduled Downtime & & & \\
\hline Unscheduled Downtime & & & \\
\hline Engineering Time & & $\begin{array}{c}\text { Operational } \\
\text { Effritures }\end{array}$ & \\
\hline Standby Time & & $\begin{array}{l}\text { Ejhelency Losses } \\
\text { (User Domain) }\end{array}$ & \\
\hline \multirow{3}{*}{ Productive Time } & & $\begin{array}{c}\text { Rate Efficiency } \\
\text { Losses } \\
\text { (Sugplier and User Domain })\end{array}$ & \\
\hline & & \begin{tabular}{|c|} 
Assignable Qualiy \\
Efficiency Losses \\
(Supplier and User Domain)
\end{tabular} & \\
\hline & & $\begin{array}{l}\text { Theoretical } \\
\text { Production Time } \\
\text { for Effective Units }\end{array}$ & \\
\hline
\end{tabular}

\section{Conclusion}

In recent years, the semiconductor manufacturing industry has high development, which makes more demands to the automation software technology. Currently, much more related researches are focused on improvements of manufacturing process. This paper discusses production equipment itself, presents TEA (Tool Efficiency Analysis) model which is based on SEMI standard, and also considers equipment performance and efficiency, finally verifies its effectiveness. This model would be useful to monitor tool behavior and analyzed tool performance automatically.

\section{Reference}

1. SEMI Standards: E10, E79. .

2. Generic Model For Communications and Control Of Manufacturing Equipment(GEM). SEMI E30-1000 .

3. Stability analysis of double EWMA run-to-run control with metrology delay. Good R,Qin S J. Proc. of American Control Conference . 2002

4. "FACTORYworks System Architecture Overview"Version2.5. Brooks Automation. . 2002

5. 《SEMI Equipment Communication Standard 1 Message Transfer》. Global Information and Control Committee. . 1999
6. 《High-Speed SECS Message Services (HSMS) Generic Services》. Global Information and Control Committee. . 2002

7. 《SEMI Equipment Communication Standard 2 Message Content》. Global Information and Control Committee. . 2000

8. A Drumea C. Popescu "Finite state machines and their applications in software for industrial control[C]" ,Electronics Technology: Meeting the Challenges of Electronics Technology Progress 2004. 27th International Spring Seminar on, vol. 1 pp. 25-29 2004.

9. V. Estivill-Castro R. Hexel "Logic labelled finite-state machines and control/status pull technology for model-driven engineering of robotic behaviours" ,Proc. 26th InternationalConference on Software \& Systems Engineering and their Applications, May 2015.

10. D. Bresolin, K. El-Fakih, T. Villa, N. Yevtushenko, "Deterministic Timed Finite State Machines: Equivalence Checking and Expressive Power", Proceedings of the 7th InternationalSymposium on Games Automata Logics and Formal Verification, pp. 203-216, 2014. 